\title{
Differences in Diving Behaviour Optimality May Cause Differences in Reproductive Success in Chinstrap Penguins: A Cases Study
}

\author{
Yoshihisa Mori*
}

Department of Animal Sciences, Teikyo University of Science, 2525 Yatsusawa, Uenohara, Yamanashi 409-0193, Japan

\begin{abstract}
Bio-logging is a useful technique for obtaining information on foraging behaviour, physiology, and environmental conditions from animals in marine ecosystems. By integrating this information, researchers can investigate the ecology of general prey-predator system in terms of their optimal behaviour with the help of theoretical models. In the present study, I analyse the diving behaviour of two chinstrap penguins using an index of diving behaviour optimality as a case study. Because of small sample size in the study, I demonstrate possibility to prove the association between calculated optimality index and breeding success in birds and how it basically would be possible if more individuals would be included in analyses. This index is the proportion of observed dive time to "standard" dive time. Standard dive time is defined as an "optimal" dive time that maximises the proportion of bottom time to the duration of a dive cycle for a given travel time. Using this index, I found a difference in the optimality of diving behaviour and prey conditions experienced between birds, which may cause differences in chick growth rate. Because many dives have already been recorded using bio-logging techniques, using this index to analyse diving behaviour could give new insights into the foraging ecology of top predators in marine ecosystems.
\end{abstract}

Keywords: Behavioural index, Bio-logging, Diving, Optimal model, Optimality.

\section{INTRODUCTION}

Diving animals such as seabirds and marine mammals play vital roles as some of the top predators in marine ecosystems by helping to control prey populations. However, direct observation of foraging behaviour of those predators is difficult. Bio-logging is a technique using data loggers to measure and record phenomena in or around free-ranging organisms that are beyond the boundaries of human visibility or experience [1]. Using appropriate sensors, researchers can measure temperature, heart rate, acceleration, magnetic field, light level and GPS signals, as well as water pressure. These measurements provide large amounts of information about the foraging ecology of study animals, including data on behavioural patterns, physiological conditions, and environmental conditions.

By integrating these data, researchers can consider relationships between behaviour and physiological and environmental conditions in diving animals in terms of foraging behaviour optimality. Since the late 1980s, several optimal foraging models predicting optimal diving behaviour under given conditions have indicated that (1) optimal dive time should increase with increasing foraging depth [2,3]; (2) optimal dive depth is shallower than the depth at which prey density is highest [4]; (3) large animals should make longer and deeper dives than smaller animals [5]; (4) anaerobic diving is profitable under some conditions [6-8]; (5) prey patch

*Address correspondence to this author at the Department of Animal Sciences, Teikyo University of Science, 2525 Yatsusawa, Uenohara, Yamanashi 409-0193, Japan; Tel: +81-554-63-6876; Fax: +81-554-63-4431;

E-mail: moripe@ntu.ac.jp quality affects optimal dive time $[9,10]$, making it possible to estimate prey patch quality from diving behaviour, assuming the animal makes dives that are optimal for a given prey patch quality [10]; and (6) optimal dive time should be shorter if the predation risk is high [11]. Most of these predictions are supported by empirical data.

However, theoretical studies have not always been the precursors of empirical studies. Thus, many empirical data can be reanalysed in light of the recent advances in optimality theory that have been gained from models. For example, most optimal diving models have been published since the late $1990 \mathrm{~s}$, which means that empirical studies published before this time did not consider models. Although unsurprising, this makes it interesting to reinterpret past empirical studies, taking into consideration recently developed theory. Here I demonstrate such a reanalysis by using the diving behaviour of chinstrap penguins, Pygoscelis antarctica, as reported in Mori $[12,13]$ and by applying a diving index that was recently formulated by Mori et al. [14], the proportion of the observed dive time to the standard dive time (POS).

Mori $[12,13]$ reported on the diving behaviour and chick growth rates of two male chinstrap penguins. One male (C9005) made significantly deeper but shorter and less frequent dives during each foraging trip than did the other male (C9014), and reproductive success, as measured by chick growth rate, was greater for $\mathrm{C} 9014$ than for C9005. It is suggested that this difference in reproductive success was due to differences in prey density encountered during foraging trips [13], but it was not known how this difference in prey density should affect diving behaviour or whether both birds were making optimal dives. 
In 2007, Mori et al. developed a new diving index, POS, the proportion of observed dive time to "standard" dive time [14]. The standard dive time is defined as an "optimal" dive time that maximises the proportion of bottom time to the duration of the dive cycle for a given travel time. Thus, the POS can be an index of optimality of diving behaviour under given conditions.

In the present study, the diving behaviour of the penguins studied by Mori $[12,13]$ was reanalysed using the POS index as a case study. Differences in diving behaviour and reproductive success between the birds are compared from the point of view of diving behaviour optimality and prey conditions. Because of small sample size in the study, it is not possible to directly prove the association between calculated optimality index and breeding success in birds. Thus, the aim of the study is to demonstrate possibility to prove the association and how it basically would be possible if more individuals would be included in analyses.

\section{METHODS}

\section{Data Collection and Analysis}

The data set used in the present study was previously discussed by Mori [12,13], and these studies can be referred to for details. Dive data were collected from two male chinstrap penguins (C9005 and C9014) from late December 1990 to mid-January 1991 at Seal Island, the South Shetland Islands, Antarctica $\left(60^{\circ} 59.5^{\prime} \mathrm{S}, 55^{\circ} 24.5^{\prime} \mathrm{W}\right)$. Data were collected using time-depth recorders (TDRs) that were $2.5 \mathrm{~cm}$ in diameter, $9 \mathrm{~cm}$ in length, and $80 \mathrm{~g}$ in weight in air $(34.5 \mathrm{~g}$ in seawater) with the battery. The TDRs (TDR-20S, Yanagikeiki Co., Ltd. Tokyo) used in this study continuously recorded dives $\geq 1 \mathrm{~m}$ in depth and $\geq 0.3 \mathrm{~min}$ in duration by scratching a recording tape with a stylus. The TDRs were attached to feathers on the middle of the backs of each bird with quick-setting epoxy glue and two plastic ties. Each bird had two eggs at the time of attachment, and the chicks hatched between 31 December 1990 and 2 January 1991. Both chicks were individually marked with picric acid for identification, and their body mass and bill length were measured every 5 days (09:00-11:00 h) until 19 January 1991.
The continuous diving records from the recording tapes were enlarged and digitised. Dives that were recorded during the incubation period and that were less than $5 \mathrm{~m}$ in depth or $20 \mathrm{~s}$ in duration were excluded from analysis. In total, 1087 and 1550 dives for 13 and 11 foraging trips were recorded for C9005 and C9014, respectively. These dives were split into 90 and 77 dive bouts, respectively, on the basis of each bout ending criteria (5.4 min and $9.4 \mathrm{~min}$ ) determined by $\log$ frequency model $[15,16]$. Further analysis was made on the scale of dive bouts, which are considered to correspond with foraging behaviour on a prey patch [17].

\section{Proportion of the Observed Dive Time to the Standard Dive Time (POS)}

Proportion of the observed dive time to the standard dive time is obtained by dividing the standard time by observed dive time. To obtain the standard dive time for a given travel time, I adopted a rate maximisation model as follows (See [14] for details). The model contained three variables: travel time, Tt, spent travelling from the water surface to a foraging patch and back to the surface; patch residence time (bottom time), $T r$, spent feeding in the foraging patch; and time spent at the surface, $T s$. Diving time equalled $T t+T r$ and was supposed to be an increasing function of the time spent at the water's surface, $T s$. That is, $T t+T r=f(T s)$. Dive time plus surface time was a dive cycle, which was a unit of diving. The standard dive time was defined as the dive time that maximised the rate of bottom time to the dive cycle $P$, or $[f(T s)-T t] /[f(T s)+T s]$. When the physiological constraints, or the relationship between dive time and surface time needed for the dive, $f(T s)$, are known, one can obtain the dive time that maximises $P$ for a given travel time $T t$ by seeking the Ts that maximises $P$. Using POS, diving behaviour between individuals can be compared in terms of optimality, even if their diving depths are different.

To obtain the relationship between dive time and the surface time associated with dive time in the present study, I used the regression function of dive time in $\mathrm{min}, u$, to surface time in min, s. In practice I used surface time class (every 1 $\mathrm{min}$ ) and mean dive time for each class. The regression functions were $u=2.0 \times \operatorname{Exp}(1-0.63 s)$ and $2.0 \times \operatorname{Exp}(1-0.67$ s) for C9005 and C9014, respectively (Fig. 1). Travel time or

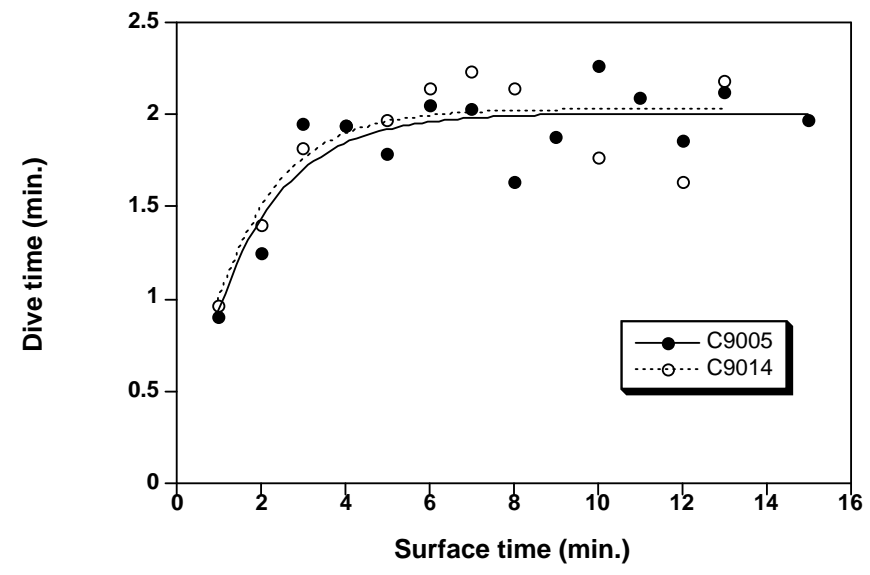

Fig. (1). Pygoscelis antarctica. Dive time and surface time associated with the dive time for two chinstrap penguins, C9005 (closed circles with a solid line) and C9014 (open circles with a dotted line). Regression lines are shown. 
bottom time is needed for calculation of the POS, but these parameters were not exactly measured and are inapplicable to the data set of the present study, because diving undulations of some dives were not clear. Thus, I estimated travel time by dividing 2 times the dive depth by the assumed vertical swimming speed of $1.0 \mathrm{~m} / \mathrm{s}$. Because the average swimming speed of penguins is $2.0 \mathrm{~m} / \mathrm{s}$ [18], the birds in the present study were assumed to have dived at an angle of $30^{\circ}$ in the water column. Although there is no information on the dive angle of the birds, Sato et al. [19] reported that the mean body angle during diving in macaroni penguins, $\mathrm{Eu}$ dyptes chrysolopus, which are similar in size to chinstrap penguins, was around $30^{\circ}$. Therefore, the assumption of dive angle in the present study seems reasonable. After calculating the standard dive time, I calculated the POS for each dive bout for each bird. Because the travel time was calculated as described above, travel time for some dives exceeded dive time. These dives were excluded from the analysis. In total, the POS was calculated for 68 and 77 dive bouts when the vertical swimming speed was $1.0 \mathrm{~m} / \mathrm{s}$ for C9005 and C9014, respectively.

\section{RESULTS}

When vertical swimming speed was assumed to be 1.0 $\mathrm{m} / \mathrm{s}$, mean $( \pm \mathrm{SD})$ POS during a bout was $0.84 \pm 0.13(\mathrm{n}=$ $68)$ and $1.00 \pm 0.13(\mathrm{n}=77)$ for $\mathrm{C} 9005$ and $\mathrm{C} 9014$, respectively (Fig. 2). The mean POS of C9014 was not different from 1.0 (Wilcoxon signed rank test; $p=0.65$ ), whereas that of C9005 was different from $1.0(\mathrm{p}<0.0001)$, suggesting that C9014's dive time did not differ from the standard dive time, whereas C9005's dive time was too short. There was a difference in the mean POS's of the individuals, with C9014 having a greater POS than C9005 (Mann-Whitney U-test; U $=775, \mathrm{p}<0.0001$ ).

For $\mathrm{C} 9005$, the POS was positively correlated with dive depth (Spearman's rank correlation, $0.47, \mathrm{p}<0.001$ ), but the same was not found for C9014 (Spearman's rank correlation, $0.05, \mathrm{p}=0.69)$. The number of dives during a bout was not correlated with the POS for either bird.

\section{DISCUSSION}

The standard dive time calculated in the present study maximises the proportion of bottom time to dive cycle for a given travel time. Therefore, if penguins make a foraging dive that maximises this proportion, then the POS should be 1.0. In practice, the POS of C9014 was almost 1.0 when the vertical speed was assumed to be $1.0 \mathrm{~m} / \mathrm{s}$, but the POS of C9005 was less than 1.0 and significantly less than that of C9014. These findings suggest the possibility that C9014 adjusted his time budget during a dive cycle to function nearly optimally, whereas C9005 made dives that were too short to be optimal. This deviation from optimal dive time may reduce efficiency in the energy intake rate, affecting provisioning behaviour. It should be noted that C9014's chick had a higher growth rate than did C9005's chick [13], which is consistent with the observed difference in diving behaviour optimality between the birds.

Another possible explanation for the individual differences in POS is that the birds encountered different prey densities in foraging patches. The birds in the present study fed mainly on krill, Euphausi superba [12], which distribute patchily with varying density. Many optimal patch use models, such as the marginal value theorem [20], have concluded that animals foraging in better prey patches should forage in these patches for longer. Considering the diving behaviour of air-breathing animals, it is predicted that even if diving depth is the same, the optimal dive time should be longer when prey patch quality is better $[9,10]$. These predictions are supported by empirical data (e.g. [21, 22]). If C9014 encountered better prey patches more frequently than did C9005, then even if their dive angle and swimming speed were the same, C9014 would have a greater POS, as found in the pre-

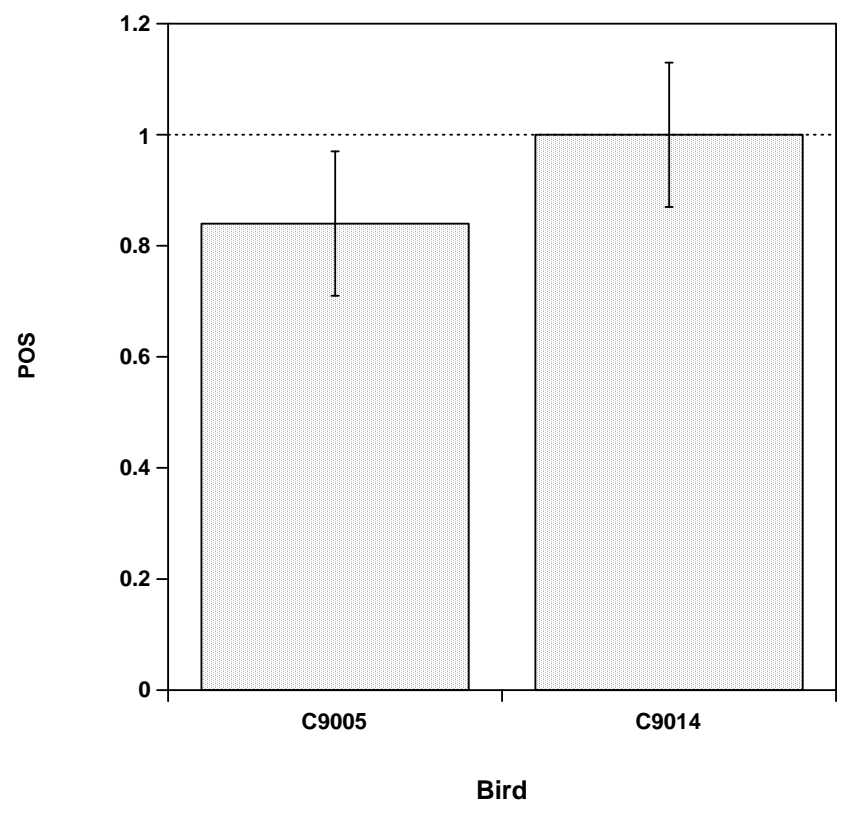

Fig. (2). Pygoscelis antarctica. Mean $( \pm \mathrm{SD})$ proportion of the observed dive time to the standard dive time (POS) for two chinstrap penguins, C9005 and C9014. 
sent study. In practice, Mori [13] suggested that the prey density encountered during a foraging trip was greater for C9014 than for C9005.

However, the POS was not correlated with the number of dives during a foraging bout for either bird, although it is predicted that the number of dives during a foraging bout should be positively correlated with prey patch condition [9]. In addition, the POS was positively correlated with dive depth for C9005. If the POS is an indicator of prey density in a patch, this suggests that prey density was positively correlated with water depth at least until $100 \mathrm{~m}$, which is not necessarily consistent with the vertical distribution of krill around Seal Island, which was investigated during the study period by the Japanese Fishery Agency [23] using an echosounder. The individual difference in POS found in the present study suggests that the birds made foraging dives differently in terms of optimising their time budget during a dive cycle and in terms of prey density. These differences may have caused the observed differences in chick growth rate between the birds.

The sample size in the present study is small. Thus, it should be noted that these two individuals served as an example of using a new method, rather than to prove the association between the index and chick growth rate. The POS is a newly developed diving index that should give experts a better understanding of the optimality of foraging diving and prey patch conditions. Because numerous dives have been recorded using bio-logging techniques, using this index to analyse the diving behaviours of seabirds could give new insights into the foraging ecology of top-predators in marine ecosystems.

\section{ACKNOWLEDGEMENTS}

This study was supported by Grant-in-Aid for Scientific Research (KAKENHI 19570027) of the Japanese Society for the Promotion of Science.

\section{CONFLICT OF INTEREST}

The author(s) confirm that this article content has no conflicts of interest.

\section{REFERENCES}

[1] Boyd IL, Kato A, Ropert-Coudert Y. Bio-logging science: sensing beyond the boudaries. Mem Natl Inst Polar Res (Spec Issue) 2004; 58: $1-14$.
[2] Kramer DL. The behavioural ecology of air breathing by aquatic animals. Can J Zool 1988; 66: 89-94.

[3] Houston AI, Carbone C. The optimal allocation of time during the diving cycle. Behav Ecol 1992; 3: 255-65.

[4] Mori Y. Optimal choice of foraging depth in divers. J Zool 1998; 245: 279-83.

[5] Mori Y. Optimal diving behaviour for foraging in relation to body size. J Evol Biol 2002; 15: 269-76.

[6] Ydenberg RC, Clark CW. Aerobiosis and anaerobiosis during diving by western grebes: an optimal foraging approach. J Theor Biol 1989; 139: 437-49.

[7] Carbone C, Houston AI. The allocation of time over the dive cycle: an approach based on aerobic and anaerobic respiration. Anim Behav 1996; 51: 1247-55.

[8] Mori Y. The optimal allocation of time and respiratory metabolism over the dive cycle. Behav Ecol 1999; 10:155-60.

[9] Mori Y. The optimal patch use in divers: optimal time budget on the number of dive cycles during bout. J Theor Biol 1998; 190: 187-99.

[10] Mori Y, Takahashi A, Mehlum F, Watanuki Y. An application of optimal diving models to diving behaviour of Brünnich's guillemots. Anim Behav 2002; 64: 739-45.

[11] Heithaus MR, Frid A. Optimal diving under the risk of predation. J Theor Biol 2003; 223: 79-92.

[12] Mori Y. Dive bout organization in the chinstrap penguins at Seal Island, Antarctica. J Ethol 1997; 15: 9-15.

[13] Mori Y. Individual diving behavior, food availability and chick growth rates in chinstrap penguins. Waterbirds 2001; 24: 443-5.

[14] Mori Y, Mitani Y, Watanabe Y, Sato K. A behavioral indicator of prey patch richness derived from diving behavior: the proportion of residence time to the standard time. Isr J Ecol Evol 2007; 53: 34754.

[15] Sibly RM, Nott HM, Fletcher DJ. Splitting behaviour into bouts. Anim Behav 1990; 39: 63-9.

[16] Martin P, Bateson P. Measuring behavior, $2^{\text {nd }}$ ed. Cambridge: Cambridge University Press 1993

[17] Boyd IL. Temporal scales of foraging in a marine predator. Ecology 1996; 77: 426-34.

[18] Sato K, Watanuki Y, Takahashi A, et al. Stroke frequency, but not swimming speed, is related to body size in free-ranging seabirds, pinnipeds and cetaceans. Proc Biol Sci 2007; 274: 471-7.

[19] Sato K, Charrassin J-B, Bost C-A, Naito Y. Why do macaroni penguins choose shallow body angles that result in longer descent and ascent durations? J Exp Biol 2004; 207: 4057-65.

[20] Charnov EL. Optimal foraging: the marginal value theorem. Theor Popul Biol 1976; 9: 129-36.

[21] Mori Y, Boyd IL. The behavioral basis for nonlinear functional responses and optimal foraging in Antarctic fur seals. Ecology 2004; 85: 398-410.

[22] Mori Y, Watanabe Y, Mintani Y, Sato K, Cameron MF, Natio Y. A comparison of prey richness estimates for Weddell seals using diving profiles and image data. Mar Ecol Prog Ser 2005; 295: 257-63.

[23] Japanese Fishery Agency. The $6^{\text {th }}$ Antarctic Ocean survey cruise of JFA R.V. Kiyo-maru. (in Japanese) Tokyo: JFA 1993. 